\title{
Stroke and coronary heart disease in mild hypertension: risk factors and the value of treatment
}

\author{
MEDICAL RESEARCH COUNCIL WORKING PARTY
}

\begin{abstract}
Further analyses of the Medical Research Council's trial of drug treatment of mild hypertension were carried out to provide more detailed information on the benefits associated with treatment in various subgroups. The four main considerations in establishing a rational treatment policy were, firstly, the significant reduction in the stroke rate with active treatment; secondly, the absence of a significant overall treatment effect on myocardial infarction; thirdly, the knowledge that of 100 untreated men in the highest risk group (those aged 55-64 with high systolic pressure at entry who smoked), five would be expected to suffer a stroke and 10 a coronary event within five years; and, fourthly, the cost, in clinical and financial terms, of prolonged treatment. In the high risk group of 100 men treatment with bendrofluazide would result in the prevention of three or four of the five strokes but would have little effect on the expected numbers of myocardial infarctions. Treatment with propranolol in non-smoking men in the highest age and blood pressure categories would lead to a reduction in the number having strokes from three to one or two and might possibly reduce the number experiencing myocardial infarction from seven to four. Smokers treated with propranolol would not be expected to benefit. In women avoiding smoking was particularly important. The considerations for preventing stroke were similar to those in men, but no clear guideline was possible on the effect of lowering blood pressure for preventing myocardial infarction in women.

Drug treatment reduces the attack rate of certain events in mild hypertension but should not be prescribed routinely for all patients with the disorder.
\end{abstract}

\footnotetext{
MEMBERS OF WORKING PARTY WERE: Professor Sir Stanley Peart (chairman), Mrs G R Barnes (until 1983), Mr P J Brennan, Mr P M G Broughton, Professor Sir Colin Dollery, Dr K G Green (until 1983), Dr M F Hudson, Dr A F Lever, Dr T W Meade, Dr W E Miall (secretary until 1983), Mr K Rennolls, Professor G A Rose, the late Dr B C Smith (until 1980), Dr P Wilding (until 1977), Dr G Greenberg (secretary).
}

Correspondence to: Professor W S Peart, MRC Epidemiology and Medical Care Unit, Northwick Park Hospital, Harrow, Middlesex HA1 3UJ.

\section{Introduction}

The Medical Research Council's trial of drug treatment of mild hypertension' showed that bendrofluazide significantly reduced the rate of stroke and that propranolol probably reduced the rate of stroke in both sexes and the rate of myocardial infarction in non-smoking men. This paper presents more detailed results on myocardial infarction, stroke, and all cardiovascular event rates (the last being almost the sum of rates of myocardial infarction and stroke). The paper also presents the benefits associated with treatment in various subgroups and reports on further analyses of the trial data in which multiple logistic regression was used to adjust for the joint confounding effects of risk factors.

Finding that drug treatment reduces the attack rate of certain events should not automatically lead to a decision to prescribe for all patients with mild hypertension, and these results, delineating the main risk factors and those groups most likely to benefit from treatment, may help in clinical management. So far as possible benefits of treatment must be balanced against disadvantages, particularly the inconvenience to the patient of long term treatment and adverse reactions, but also the financial costs.

\section{Patients and methods}

Most aspects of the trial design have been described' and only essential details are given here. The 17354 participants were men and women aged 35-64 at entry who had sustained diastolic (phase V) pressures of $90-109 \mathrm{~mm} \mathrm{Hg}$ over the screening period. Patients were randomly allocated at entry to groups taking either bendrofluazide $(n=4297)$ or propranolol $(n=4403)$ or placebo tablets $(n=8654)$, with roughly equal numbers of men and women in each group. Data on age, height and body weight (and hence body mass index), blood pressure, number of cigarettes smoked, electrocardiographic findings, and serum cholesterol concentration were available at entry and at regular intervals throughout the trial. Follow up lasted for up to five and a half years, and all changes of treatment, cardiovascular events, and deaths from any cause during this time were monitored.

\section{ANALYSES}

Three methods of analysis were used.

Comparison of unadjusted event rates in subgroups-Tables of event rates 
and benefits associated with treatment are presented according to a combination of age, blood pressure at entry, and smoking habit. If $r_{p}$ and $r_{t}$ are the event rates in the placebo and active treatment subgroups, respectively, then relative risk $=\mathrm{r}_{\mathrm{t}} / \mathrm{r}_{\mathrm{p}}$ and is less than 1.0 if the treatment is beneficial. Relative benefit is defined as 1.0 minus relative risk and is multiplied by 100 to express relative benefit as a percentage. Absolute benefit is defined as the reduction in event rate $\left(r_{p}-r_{t}\right)$. The number of patients to be treated for five years in order to prevent one event is 200 divided by absolute benefit. Calculations were usually based on comparisons of the active and placebo treatment groups, the placebo group being large and providing the best baseline data available. $p$ Values presented take no account of the fact that many comparisons were made. Consequently less confidence should be placed on any particular tabulated $p$ value than if the $p$ value had resulted from a single comparison. Additional problems arising from these straightforward comparisons include the small numbers of patients and events in certain subgroups. Inferences must be drawn with care in these cases, where changes from the randomised drug regimen and differing withdrawal rates from the different treatment groups may be important. Further, where correlated variables are used to define subgroups comparison of event rates may give only limited information. For instance, body mass index and the number of cigarettes smoked are inversely correlated, so the high and low body mass index subgroups will also differ significantly in smoking habit. Other methods of analysis have been used to overcome these problems.

Risk analysis with multiple logistic regression model-We estimated the relative risks associated with given changes in risk factors by using multiple logistic regression to determine the effects of changes in risk factors or treatments while taking into account the confounding effects of other risk factors. By examining the improvement in the descriptive fit of the model on including various risk factors the contributions made by the different factors may be compared with one another. The possibility of $\mathrm{J}$ shaped relations between risk variables, particularly diastolic blood pressure, and event rates was tested by seeing whether a non-linear-for example, quadratic-effect added significantly to the description of the data provided by the multiple logistic model. All first order interactions among sex, age, number of cigarettes smoked, electrocardiogram at entry, pulse rate, and treatment were also tested.

Cox's proportional hazards model makes use of the duration of follow up before events occur and was used on major subsets of the data for various outcomes. The resulting estimates of relative risk, however, were not significantly different from those obtained by using logistic regression and are therefore not presented in detail here. Fitting a model which adjusts for all the risk variables at entry and then testing the significance of fit produced by including treatment provides a test of whether the treatment has an overall effect on event rates. By contrast, when our basic model uses in treatment mean blood pressures (see below) as risk variables, testing the effect of adding the treatment factor to the model $(a)$ shows whether there is an effect of active treatment beyond that which may be ascribed to the treatment's beneficial effect on the major risk variables and $(b)$ allows us to examine whether drug treatment confers a greater benefit than can be explained by blood pressure reduction alone. (Mean in treatment pressures will be determined more precisely than the pressure at a single date-for example, six months from the start of the trial-and therefore be expected to provide more sensitive tests than if six month pressure was used. ${ }^{2}$ Mean pressures were calculated from the routine trial pressure measurements, excluding values recorded during the first three months of follow up, when the effects of regression to the mean were still pronounced.) All measurements of all variables were used until either a terminating event occurred or the trial ended.

\section{Results}

Firstly, we present the results of the risk analysis for the placebo group. This is followed by an analysis of the benefit of treatment, and, finally, we see if there were any drug specific effects.

\section{RISK FACTORS IN PLACEBO TREATMENT GROUP}

Table I gives the relative risks, with $\mathrm{p}$ values and confidence intervals, for stroke, myocardial infarction, and all cardiovascular events in relation to the classical risk factors for men and women separately. All factors except age and electrocardiographic findings are mean values observed throughout the trial. Table I is based on all risks being linearly dependent on the risk factors. Departures from this assumption are discussed below.

\section{Age}

The relative risk associated with a five year increment in age at entry was 1.37 for all cardiovascular events, 1.31 for coronary events, and 1.53 for stroke in men; in women these values were somewhat higher $(1 \cdot 64,1 \cdot 72$, and 1.65 respectively). This difference between the sexes was not significant. Analysis of the data from both sexes together, by using a quadratic term for age, gave some suggestion $(p=0.05)$ that the relative risk for a five year increase was greater in younger than older patients $(1.65$ at 45 years, 1.36 at 52 (mean age in the trial), and 1.09 at 60 ).

\begin{tabular}{|c|c|c|c|c|c|c|c|c|}
\hline & $\begin{array}{c}\text { Age } \\
(5 \text { year } \\
\text { increase })^{\star}\end{array}$ & $\begin{array}{l}\text { Smoking }(20 \\
\text { cigarettes/day } \\
\text { increase }) \dagger\end{array}$ & $\begin{array}{c}\text { Systolic } \\
\text { pressure } \\
(10 \mathrm{~mm} \mathrm{Hg} \\
\text { increase }) \dagger\end{array}$ & $\begin{array}{l}\text { Diastolic } \\
\text { pressure } \\
(4 \mathrm{~mm} \mathrm{Hg} \\
\text { increase }) \dagger\end{array}$ & $\begin{array}{c}\text { Ischaemic } \\
\text { electrocardiogram: } \\
\text { non-ischaemic } \\
\text { electrocardiogram }\end{array}$ & $\begin{array}{l}\text { Cholesterol } \\
(1 \mathrm{mmol} / 1 \\
\text { increase }) \dagger\end{array}$ & $\begin{array}{c}\text { Body mass } \\
\text { index } \\
\left(3 \mathrm{~kg} / \mathrm{m}^{2}\right. \\
\text { increase }) \dagger\end{array}$ & $\begin{array}{c}\text { Pulse rate } \\
(10 / \mathrm{min} \\
\text { increase })\end{array}$ \\
\hline \multicolumn{9}{|c|}{$\operatorname{Men}(n=3835)$} \\
\hline \multicolumn{9}{|c|}{ All cardiovascular events $(n=177)$ : } \\
\hline Relative risk & 1.37 & 1.98 & $1 \cdot 24$ & $1 \cdot 22$ & $2 \cdot 13$ & 1.22 & 0.94 & 1.03 \\
\hline p Value & $<0.0001$ & $<0.0001$ & $<0 \cdot 0001 \ddagger$ & 0.01 & 0.028 & 0.015 & 0.41 & 0.98 \\
\hline $95 \%$ Confidence interval & 1.20 to 1.57 & 1.49 to 2.65 & 1.08 to $1.43 \ddagger$ & 1.07 to 1.38 & 1.30 to 3.62 & 1.04 to 1.43 & 0.82 to 1.08 & 0.86 to 1.23 \\
\hline \multicolumn{9}{|l|}{ Myocardial infarction $(n=138)$ : } \\
\hline Relative risk & $1 \cdot 31$ & 1.89 & $1 \cdot 21$ & $1 \cdot 14$ & $2 \cdot 44$ & $1 \cdot 26$ & 0.92 & $1 \cdot 11$ \\
\hline $\mathrm{p}$ Value & 0.0002 & 0.0001 & $0.0001 \ddagger$ & 0.046 & 0.001 & 0.011 & 0.32 & $0 \cdot 31$ \\
\hline \multirow{2}{*}{\multicolumn{9}{|c|}{ Stroke $(n=42)$ : }} \\
\hline & & & & & & & & \\
\hline Relative risk & 1.53 & 1.99 & $1 \cdot 34$ & $1 \cdot 30$ & $1 \cdot 39$ & 1.05 & $1 \cdot 00$ & 0.87 \\
\hline p Value & 0.002 & 0.016 & 0.043 & $0.0001 \ddagger$ & 0.54 & 0.80 & 1.00 & 0.45 \\
\hline \multirow[t]{2}{*}{$95 \%$ Confidence interval } & $1 \cdot 17$ to $2 \cdot 01$ & $1 \cdot 14$ to $3 \cdot 48$ & 1.02 to 1.76 & 1.01 to $1.66 \neq$ & 0.48 to 4.00 & 0.76 to 1.45 & 0.76 to 1.31 & 0.62 to 1.24 \\
\hline & \multicolumn{8}{|c|}{ Women $(n=3306)$} \\
\hline \multicolumn{9}{|c|}{ All cardiovascular events $(n=55)$ : } \\
\hline Relative risk & 1.64 & $4 \cdot 41$ & $1 \cdot 15$ & & 1.64 & 1.03 & 0.93 & 1.35 \\
\hline p Value & $<0.0001$ & $<0.0001$ & $0 \cdot 16$ & NS & $0 \cdot 26$ & 0.80 & $0 \cdot 45$ & 0.038 \\
\hline $95 \%$ Confidence interval & 1.33 to 2.06 & 2.45 to 7.94 & 0.95 to 1.40 & & 0.69 to 3.84 & 0.80 to 1.33 & 0.78 to $1 \cdot 12$ & 1.02 to 1.79 \\
\hline \multicolumn{9}{|c|}{ Myocardial infarction $(n=22)$ : } \\
\hline Relative risk & $1 \cdot 72$ & $4 \cdot 62$ & $1 \cdot 15$ & & 0.07 & $1 \cdot 13$ & 1.03 & 1.27 \\
\hline p Value & 0.003 & 0.0004 & 0.28 & NS & $0 \cdot 13$ & 0.52 & 0.82 & 0.29 \\
\hline $95 \%$ Confidence interval & 1.20 to 2.45 & 1.91 to 11.22 & 0.89 to 1.48 & & 0 to $2 \cdot 20$ & 0.77 to 1.65 & 0.79 to 1.35 & 0.81 to 1.97 \\
\hline \multicolumn{9}{|l|}{ Stroke $(n=34)$ : } \\
\hline Relative risk & $1 \cdot 65$ & 3.94 & & $1 \cdot 22$ & $3 \cdot 13$ & 0.97 & $0 \cdot 88$ & $1 \cdot 44$ \\
\hline $\mathrm{p}$ Value & 0.0009 & 0.0004 & NS & $0 \cdot 10$ & 0.014 & 0.86 & $0 \cdot 28$ & 0.045 \\
\hline $95 \%$ Confidence interval & $1 \cdot 23$ to $2 \cdot 21$ & 1.84 to 8.44 & & 0.97 to 1.53 & $1 \cdot 27$ to $7 \cdot 71$ & 0.69 to 1.36 & 0.69 to 1.11 & 1.01 to 2.06 \\
\hline
\end{tabular}


TABLE II-Numbers and rates (per 1000 person years) of strokes, coronary events, and all cardiovascular events stratified by sex, smoking habit, systolic pressure at entry, age at entry, and treatment. (Data for coronary events in women not shown because so few)

\begin{tabular}{|c|c|c|c|c|c|c|c|c|c|c|c|c|c|c|c|c|c|c|c|c|}
\hline \multirow[b]{3}{*}{ Smoking } & \multirow{3}{*}{$\begin{array}{c}\text { Systolic } \\
\text { blood } \\
\text { pressure } \\
(\mathrm{mm} \mathrm{Hg})\end{array}$} & \multirow{3}{*}{$\begin{array}{c}\text { Age } \\
\text { (years) }\end{array}$} & \multicolumn{6}{|c|}{ Stroke } & \multicolumn{6}{|c|}{ Coronary events } & \multicolumn{6}{|c|}{ All cardiovascular events } \\
\hline & & & \multicolumn{2}{|c|}{ Bendrofluazide } & \multicolumn{2}{|c|}{ Propranolol } & \multicolumn{2}{|c|}{ Placebo } & \multicolumn{2}{|c|}{ Bendrofluazide } & \multicolumn{2}{|c|}{ Propranolol } & \multicolumn{2}{|c|}{ Placebo } & \multicolumn{2}{|c|}{ Bendrofluazide } & \multicolumn{2}{|c|}{ Propranolol } & \multicolumn{2}{|c|}{ Placebo } \\
\hline & & & No & Rate & No & Rate & No & Rate & No & Rate & No & Rate & No & Rate & No & Rate & No & Rate & No & Rate \\
\hline \multicolumn{21}{|c|}{ Men } \\
\hline No & $\left\{\begin{array}{l}<160 \\
\geqslant 160\end{array}\right.$ & $\begin{array}{r}\left\{\begin{array}{l}35-44 \\
45-54 \\
55-64\end{array}\right. \\
\left\{\begin{array}{l}35-44 \\
45-54 \\
55-64\end{array}\right.\end{array}$ & $\begin{array}{l}0 \\
1 \\
1 \\
0 \\
0 \\
6\end{array}$ & $\begin{array}{l}0 \\
0 \cdot 5 \\
1 \cdot 0 \\
0 \\
0 \\
4 \cdot 0\end{array}$ & $\begin{array}{l}1 \\
1 \\
1 \\
0 \\
1 \\
5\end{array}$ & $\begin{array}{l}0 \cdot 8 \\
0 \cdot 5 \\
0 \cdot 9 \\
0 \\
0 \cdot 8 \\
3 \cdot 1\end{array}$ & $\begin{array}{r}0 \\
5 \\
4 \\
1 \\
9 \\
18\end{array}$ & $\begin{array}{l}0 \\
1 \cdot 3 \\
1 \cdot 7 \\
1 \cdot 1 \\
3 \cdot 5 \\
5 \cdot 9\end{array}$ & $\begin{array}{r}3 \\
6 \\
15 \\
1 \\
8 \\
23\end{array}$ & $\begin{array}{r}2 \cdot 5 \\
3 \cdot 0 \\
14 \cdot 8 \\
2 \cdot 4 \\
6 \cdot 6 \\
15 \cdot 2\end{array}$ & $\begin{array}{r}4 \\
13 \\
5 \\
0 \\
4 \\
13\end{array}$ & $\begin{array}{l}3 \cdot 3 \\
6 \cdot 2 \\
4 \cdot 6 \\
0 \\
3 \cdot 1 \\
8 \cdot 2\end{array}$ & $\begin{array}{r}4 \\
26 \\
20 \\
4 \\
20 \\
42\end{array}$ & $\begin{array}{r}1 \cdot 7 \\
6 \cdot 6 \\
8 \cdot 8 \\
4.6 \\
7 \cdot 7 \\
13.9\end{array}$ & $\begin{array}{r}3 \\
7 \\
16 \\
1 \\
9 \\
29\end{array}$ & $\begin{array}{r}2 \cdot 5 \\
3 \cdot 5 \\
15 \cdot 9 \\
2 \cdot 4 \\
7 \cdot 4 \\
19 \cdot 4\end{array}$ & $\begin{array}{r}5 \\
14 \\
6 \\
0 \\
4 \\
19\end{array}$ & $\begin{array}{c}4 \cdot 1 \\
6 \cdot 7 \\
5 \cdot 6 \\
0 \\
3 \cdot 1 \\
12 \cdot 0\end{array}$ & $\begin{array}{r}4 \\
31 \\
25 \\
5 \\
29 \\
60\end{array}$ & $\begin{array}{r}1 \cdot 7 \\
7 \cdot 9 \\
11 \cdot 0 \\
5 \cdot 7 \\
11 \cdot 3 \\
20 \cdot 1\end{array}$ \\
\hline Yes & $\left\{\begin{array}{l}<160 \\
\geqslant 160\end{array}\right.$ & $\begin{array}{l}\left\{\begin{array}{l}35-44 \\
45-54 \\
55-64\end{array}\right. \\
\left\{\begin{array}{l}35-44 \\
45-54 \\
55-64\end{array}\right.\end{array}$ & $\begin{array}{l}0 \\
0 \\
1 \\
0 \\
1 \\
1\end{array}$ & $\begin{array}{l}0 \\
0 \\
2 \cdot 5 \\
0 \\
1 \cdot 7 \\
1 \cdot 4\end{array}$ & $\begin{array}{l}1 \\
1 \\
2 \\
1 \\
6 \\
6\end{array}$ & $\begin{array}{l}1 \cdot 5 \\
1 \cdot 3 \\
5 \cdot 2 \\
4 \cdot 6 \\
9 \cdot 8 \\
9 \cdot 3\end{array}$ & $\begin{array}{r}0 \\
4 \\
4 \\
0 \\
5 \\
14\end{array}$ & $\begin{array}{c}0 \\
2 \cdot 3 \\
6 \cdot 1 \\
0 \\
4 \cdot 3 \\
10 \cdot 1\end{array}$ & $\begin{array}{r}6 \\
11 \\
3 \\
1 \\
8 \\
14\end{array}$ & $\begin{array}{r}10 \cdot 1 \\
12 \cdot 4 \\
7 \cdot 7 \\
4 \cdot 2 \\
14 \cdot 0 \\
20 \cdot 8\end{array}$ & $\begin{array}{r}3 \\
12 \\
4 \\
2 \\
10 \\
14\end{array}$ & $\begin{array}{r}4 \cdot 4 \\
15 \cdot 3 \\
10 \cdot 4 \\
9 \cdot 2 \\
16 \cdot 6 \\
21 \cdot 9\end{array}$ & $\begin{array}{r}6 \\
17 \\
8 \\
3 \\
19 \\
30\end{array}$ & $\begin{array}{r}4 \cdot 5 \\
10 \cdot 0 \\
12 \cdot 4 \\
5 \cdot 5 \\
16 \cdot 6 \\
21 \cdot 7\end{array}$ & $\begin{array}{r}6 \\
12 \\
4 \\
1 \\
9 \\
16\end{array}$ & $\begin{array}{r}10 \cdot 1 \\
13 \cdot 5 \\
10 \cdot 3 \\
4 \cdot 2 \\
15 \cdot 9 \\
23 \cdot 8\end{array}$ & $\begin{array}{r}4 \\
13 \\
6 \\
3 \\
17 \\
20\end{array}$ & $\begin{array}{r}6 \cdot 0 \\
16 \cdot 7 \\
15 \cdot 9 \\
13 \cdot 9 \\
28 \cdot 8 \\
31 \cdot 7\end{array}$ & $\begin{array}{r}6 \\
23 \\
13 \\
3 \\
24 \\
47\end{array}$ & $\begin{array}{r}4.5 \\
13 \cdot 6 \\
20 \cdot 3 \\
5.5 \\
21 \cdot 3 \\
34.8\end{array}$ \\
\hline \multicolumn{21}{|c|}{ Women } \\
\hline No & $\left\{\begin{array}{l}<160 \\
\geqslant 160\end{array}\right.$ & $\begin{array}{l}\left\{\begin{array}{l}35-44 \\
45-54 \\
55-64\end{array}\right. \\
\left\{\begin{array}{l}35-44 \\
45-54 \\
55-64\end{array}\right.\end{array}$ & $\begin{array}{l}1 \\
1 \\
0 \\
0 \\
0 \\
2\end{array}$ & $\begin{array}{l}1 \cdot 6 \\
0 \cdot 8 \\
0 \\
0 \\
0 \\
0 \cdot 8\end{array}$ & $\begin{array}{l}0 \\
1 \\
0 \\
0 \\
1 \\
5\end{array}$ & $\begin{array}{l}0 \\
0 \cdot 8 \\
0 \\
0 \\
0 \cdot 6 \\
1 \cdot 9\end{array}$ & $\begin{array}{r}1 \\
1 \\
3 \\
0 \\
2 \\
16\end{array}$ & $\begin{array}{l}0 \cdot 8 \\
0 \cdot 4 \\
1 \cdot 5 \\
0 \\
0 \cdot 6 \\
3 \cdot 3\end{array}$ & & & & & & & $\begin{array}{l}1 \\
3 \\
0 \\
0 \\
0 \\
6\end{array}$ & $\begin{array}{l}1 \cdot 6 \\
2 \cdot 4 \\
0 \\
0 \\
0 \\
2 \cdot 5\end{array}$ & $\begin{array}{r}0 \\
2 \\
0 \\
0 \\
1 \\
10\end{array}$ & $\begin{array}{l}0 \\
1 \cdot 5 \\
0 \\
0 \\
0 \cdot 6 \\
3.9\end{array}$ & $\begin{array}{r}2 \\
3 \\
4 \\
0 \\
2 \\
28\end{array}$ & $\begin{array}{l}1.5 \\
1.2 \\
2.0 \\
0 \\
0.6 \\
5.9\end{array}$ \\
\hline Yes & $\left\{\begin{array}{l}<160 \\
\geqslant 160\end{array}\right.$ & $\begin{array}{l}\left\{\begin{array}{l}35-44 \\
45-54 \\
55-64\end{array}\right. \\
\left\{\begin{array}{l}35-44 \\
45-54 \\
55-64\end{array}\right.\end{array}$ & $\begin{array}{l}0 \\
1 \\
1 \\
0 \\
0 \\
1\end{array}$ & $\begin{array}{l}0 \\
2 \cdot 2 \\
2 \cdot 7 \\
0 \\
0 \\
1 \cdot 2\end{array}$ & $\begin{array}{l}1 \\
0 \\
1 \\
1 \\
2 \\
4\end{array}$ & $\begin{array}{l}4 \cdot 8 \\
0 \\
3 \cdot 3 \\
6 \cdot 2 \\
2 \cdot 8 \\
4 \cdot 5\end{array}$ & $\begin{array}{l}2 \\
4 \\
2 \\
2 \\
4 \\
7\end{array}$ & $\begin{array}{l}4 \cdot 3 \\
4 \cdot 3 \\
3 \cdot 3 \\
6 \cdot 2 \\
2 \cdot 8 \\
4 \cdot 2\end{array}$ & & & & & & & $\begin{array}{l}0 \\
1 \\
4 \\
1 \\
5 \\
6\end{array}$ & $\begin{array}{r}0 \\
2 \cdot 2 \\
10 \cdot 9 \\
7 \cdot 1 \\
7 \cdot 9 \\
7 \cdot 0\end{array}$ & $\begin{array}{r}1 \\
2 \\
1 \\
2 \\
4 \\
11\end{array}$ & $\begin{array}{r}4 \cdot 8 \\
5.0 \\
3 \cdot 3 \\
12 \cdot 5 \\
5 \cdot 6 \\
12 \cdot 8\end{array}$ & $\begin{array}{r}2 \\
6 \\
8 \\
2 \\
9 \\
14\end{array}$ & $\begin{array}{r}4 \cdot 3 \\
6 \cdot 4 \\
13 \cdot 4 \\
6 \cdot 2 \\
6 \cdot 3 \\
8 \cdot 5\end{array}$ \\
\hline
\end{tabular}

\section{Smoking}

In our earlier paper patients were classified as either smokers or nonsmokers. ${ }^{1}$ In this analysis smoking was treated as a continuous variable by using the mean number of cigarettes smoked throughout the trial, so that dose-response relations could be tested and departures from the logistic-linear model examined. Smoking was consistently of outstanding importance. In men the relative risk for a difference of 20 cigarettes a day was about 2.0 for all categories of events. Smoking was particularly important in women, in whom the relative risk was 4.62 for coronary events (though the event rate was low), 3.94 for stroke, and 4.41 for all cardiovascular events. The difference between men and women in the relation of smoking to events - that is, the interaction between sex and smoking - was significant for all cardiovascular events $(p=0.025)$ and for coronary events $(p=0.046)$ but not for stroke $(p=0 \cdot 11)$.

\section{Blood pressure}

For men the linearly dependent relative risks are given for both systolic ( $10 \mathrm{~mm} \mathrm{Hg}$ difference) and diastolic $(4 \mathrm{~mm} \mathrm{Hg}$ difference) pressures, both of which were significant for all categories of event. Though both were significant, these factors were not independent of one another as the apparent importance of each was increased when the other was omitted from the model fitted. For example, the relative risks in men for increasing systolic and diastolic pressures were 1.21 and 1.14 respectively, yielding an estimated relative risk for a joint increase of $1 \cdot 21 \times 1 \cdot 14=1 \cdot 38$. When diastolic pressure was omitted the estimated relative risk for a $10 \mathrm{~mm} \mathrm{Hg}$ rise in systolic pressure was $1 \cdot 31$.

For women, however, blood pressure was not shown to be a significant risk factor either for stroke or for myocardial infarction throughout the range of pressures studied (linear risk model). The between sex difference was significant $(p=0.04)$ in this respect.

In both men and women in the placebo group, however, there was a significant $(p=0.014)$ non-linear-that is, quadratic-effect of diastolic pressure for myocardial infarction. Detailed examination of the data for patients with low mean in trial pressure (diastolic pressure $<90 \mathrm{~mm} \mathrm{Hg}$ ) did not show an upturn in risk of myocardial infarction for increasingly low pressures in men, but there was some indication that this might be the case in women $(p=0.05)$. The primary interpretation of the significance of the non-linear (quadratic) effect of diastolic pressure in men (taking account of the full range of pressure) is therefore that risk of myocardial infarction does not increase uniformly with pressure but increases at an increasing rate with increasing pressure. For women the risk of myocardial infarction in those with low mean in trial pressure decreased with increasing mean pressure, if anything, but the slope of decline was very small, as was the event rate for myocardial infarction in women. There was no significant $J$ shaped quadratic effect in either actively treated group.

These results failed to confirm the suggested J shaped dependency of risk on mean in trial diastolic blood pressure reported by others, ${ }^{34}$ and this conclusion remained when we restricted our analysis to patients with electrocardiographic evidence of ischaemia at entry to the trial.

\section{Ischaemic electrocardiographic changes at entry}

The effect of ischaemic electrocardiographic changes (Minnesota codes $1_{1-2}, 4_{1-3}$, or $5_{1-2}$ ) at entry differed in men and women. For men the relative risk associated with an ischaemic electrocardiogram at entry was 2.44 for coronary events; in women this factor was not significant. This difference between the sexes was significant $(p=0 \cdot 008)$. An ischaemic electrocardiogram was a significant risk factor for stroke in women (relative risk $3 \cdot 13 ; p=0.014$ ), whereas it was not for men. The difference between the sexes was not significant.

\section{Serum cholesterol concentration}

Serum cholesterol concentration was significant for coronary events in men (relative risk 1.26 for an increase of $1 \mathrm{mmol} / \mathrm{l} ; \mathrm{p}=0.011$ ) but not in women.

\section{Body mass index}

Body mass index did not make a significant contribution to the risk of coronary events or strokes among untreated patients of either sex, though there was some indication that it might be predictive of sudden death in women. This differs from our previous results, ${ }^{1}$ where body mass index was found to be a significant risk factor for coronary events, though there was some categorisation of continuous variables.

\section{Pulse rate}

Pulse rate was a significant risk factor in untreated subjects only for stroke in women (relative risk $1 \cdot 44 ; p=0 \cdot 045$ ).

\section{EFFECT OF TREATMENT ADJUSTED FOR RISK VARIABLES AT ENTRY}

Table II shows the numbers and rates of events according to sex, 
smoking habit, systolic blood pressure, age, and treatment regimen. Quite consistently in the various groups treatment was on the whole beneficial against stroke, the absolute benefit increasing with levels of risk factors. For coronary events there was a suggestion that a possibly beneficial effect of propranolol also increased with the levels of risk factors, though when pooled across sex and smoking habit the estimated relative benefit of propranolol on this event rate was only $13 \%$, which was not significant. The graphs for bendrofluazide (smoking plus non-smoking) and placebo (smoking plus non-smoking) in figure 1 show that bendrofluazide was highly effective $(p<0.0001)$ against stroke, with a relative benefit of $68 \%$. Propranolol, however, though possibly reducing the stroke rate (relative benefit $30 \%$ ), did not do so significantly. Comparison of the stroke rates of patients taking propranolol with those of patients taking placebo for smokers and non-smokers separately (see figure 1) strongly suggests that propranolol was effective against stroke in non-smokers but ineffective in smokers, even though the interaction between type of treatment (bendrofluazide or propranolol) and smoking did not reach a formal level of significance (this interaction being just significant $(p=0.03)$ when smoking was treated as a categorical variable ${ }^{1}$.

\section{EFFECT OF TREATMENT ADJUSTED FOR IN TRIAL RISK VARIABLES}

Treatment and in trial values of risk variables were not independent; pressure was lowered by treatment, and pulse rate and other relevant factors may also have been affected. Whether there was any additional benefit of treatment beyond that achieved by lowered levels of measured risk factors could be tested by examining whether treatment made any further contribution to a fitted logistic regression which already took into account the in trial risk variables.

Figure 2 shows stroke rates (sexes pooled) for the bendrofluazide, propranolol, and placebo treatment groups, the second two groups being subdivided by smoking habit, plotted against systolic pressure six months after entry into the trial. The stroke rates at all levels of in trial pressure were consistently lower for the bendrofluazide group (smoking plus non-smoking) than for the corresponding placebo group. If the beneficial effect of bendrofluazide on stroke rate had been mediated only through its pressure lowering effect we would have expected that patients with the same in trial pressure would have had the same event rate whether taking bendrofluazide or placebo. In fact, it might be expected that those who had achieved a given mean pressure with placebo would have had a lower event rate than those who had achieved that pressure only after treatment with bendrofluazide. The fact that the converse was the case suggests that there may be a beneficial effect of bendrofluazide on stroke rate which goes beyond that due to its hypotensive effect.

In non-smokers the picture for propranolol was closely similar (fig 2 ) to that for bendrofluazide, but in smokers the rates for propranolol were in general higher than those for placebo.

Logistic regression confirmed the extra beneficial effect of bendrofluazide on stroke rate (relative benefit $47 \% ; p=0.04$ ), but for propranolol no overall extra benefit was detected (smoking plus non-smoking) and the treatmentsmoking interaction term (which, if clearly established, would have added to

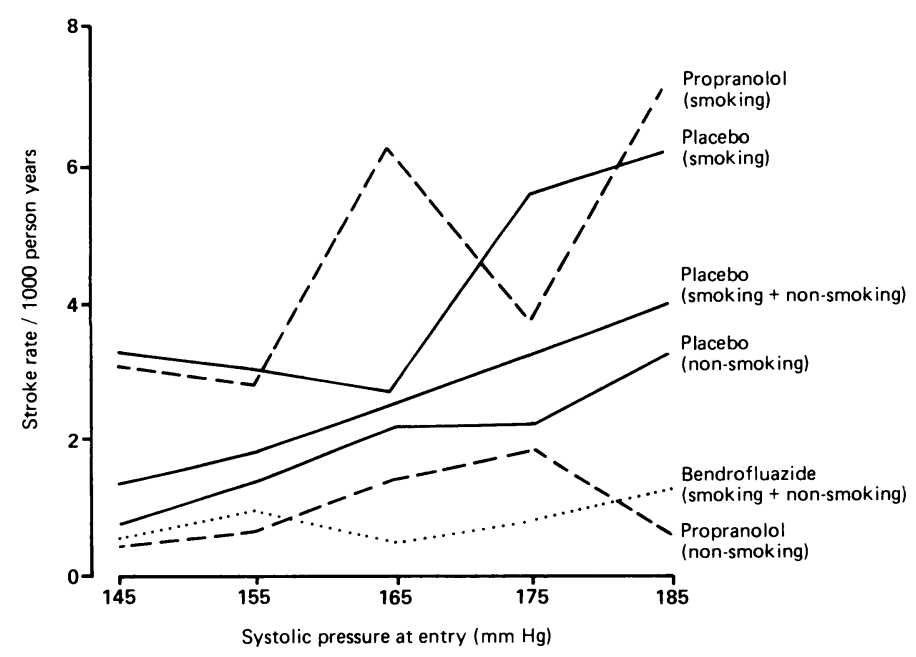

FIG 1-Stroke rate/1000 person years and systolic pressure at entry, treatment, and smoking state. Rate shown for systolic pressure of $165 \mathrm{~mm} \mathrm{Hg}$ at entry calculated from patients with systolic pressures of $160-169 \mathrm{~mm} \mathrm{Hg}$ at entry.

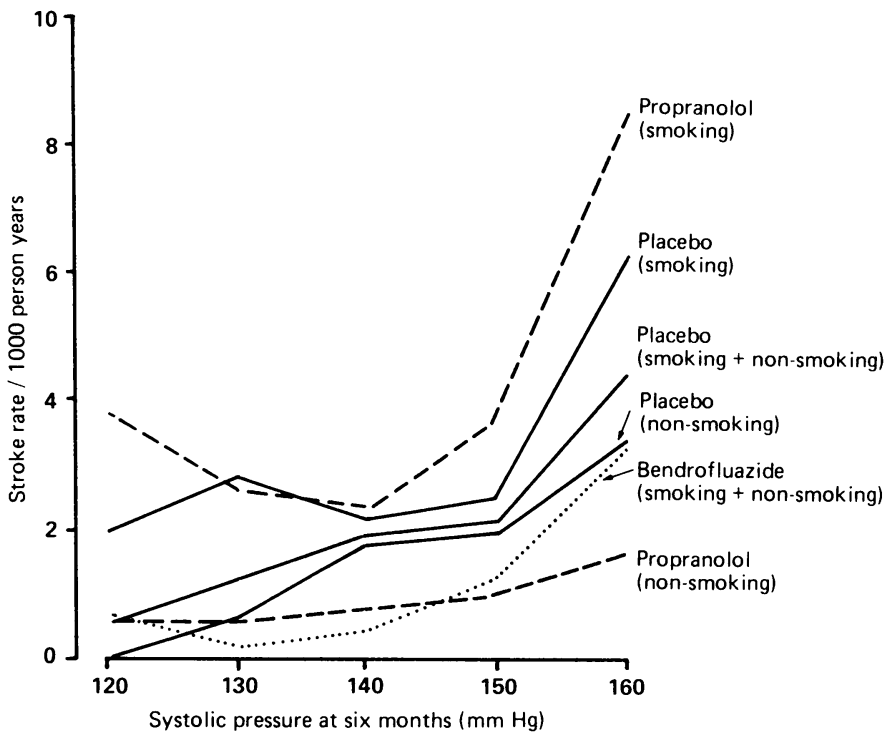

FIG 2-Stroke rate/1000 person years and systolic pressure after six months' treatment and smoking state. Rate shown for systolic pressure of $140 \mathrm{~mm} \mathrm{Hg}$ at six months calculated from patients with systolic pressures of $135-144 \mathrm{~mm} \mathrm{Hg}$ at six months.

the evidence of differing effects of propranolol in smokers and non-smokers in another trial ${ }^{5}$ ) was not significant. There was no evidence (table II) of an adverse effect of treatment on myocardial infarction.

\section{Discussion}

These results may be useful in three main respects: in delineating the risk factors and emphasising the particular importance of smoking as a risk factor and, possibly, as a factor affecting the choice of treatment; in identifying those categories of mild hypertension where substantial absolute benefit from treatment was achieved; and in showing that both bendrofluazide and propranolol may act to reduce stroke rates by some as yet unidentified process additional to their hypotensive effect.

Probably the best advice which can be given to patients with mild hypertension is that they should not smoke; and this may be even more important for women, in whom the relative risks associated with smoking were particularly high.

Not only was smoking important as a risk factor but there was also some suggestion that it influenced drug efficacy. The lack of benefit associated with propranolol might be related to the pressor effect of high plasma adrenaline concentrations found in smokers taking propranolol, ${ }^{6}$ but we have no direct evidence. It seems reasonable to conclude that propranolol, possibly oxprenolol, ${ }^{5}$ and, in the absence of evidence to the contrary, other $\beta$ blockers also, may reduce event rates much less in smokers than in non-smokers, and when used with this aim in the treatment of mild hypertension these drugs should be reserved for non-smokers.

Our results, in general, confirm published findings on the classical risk factors, though we found a significant difference between the sexes in respect of the risk of coronary events due to smoking. The only classical risk factor which our data failed to show as having independent significance was body mass index, though this factor was correlated with cholesterol value, which is significantly associated with event rates in men.

The importance of the findings on risk factors in untreated patients arises from the fact that the absolute benefit of treatment is directly dependent on the event rate in this group. This untreated event rate depends not only on the blood pressure-that is, the risk variable which may be reduced by treatment of hypertension-but also on all the other risk factors. Hence a greater absolute benefit may be obtained by reducing pressures in high risk patients than by reducing pressures in low risk patients by the same amount. Tables III-V illustrate this point. The high risk patient derives much greater absolute benefit when treated by bendrofluazide than does 
TABLE III-Levels of risk factors assumed in two male profiles: patient generally low on most risk factors but with high blood pressure; patient generally high on most risk factors

\begin{tabular}{|c|c|c|c|c|c|c|c|}
\hline & \multicolumn{7}{|c|}{ Risk factors } \\
\hline & $\begin{array}{c}\text { Age } \\
\text { (years) }\end{array}$ & $\begin{array}{l}\text { Serum cholesterol } \\
(\mathrm{mmol} / \mathrm{l})\end{array}$ & $\begin{array}{c}\text { Body mass index } \\
\left(\mathrm{kg} / \mathrm{m}^{2}\right)\end{array}$ & $\begin{array}{c}\text { Ischaemic } \\
\text { electrocardiogram }\end{array}$ & Cigarettes/day & $\begin{array}{l}\text { Systolic pressure } \\
(\mathrm{mm} \mathrm{Hg})\end{array}$ & $\begin{array}{l}\text { Diastolic pressure } \\
(\mathrm{mm} \mathrm{Hg})\end{array}$ \\
\hline $\begin{array}{l}\text { Low risk } \\
\text { High risk }\end{array}$ & $\begin{array}{l}45 \\
65\end{array}$ & $\begin{array}{l}5 \\
8\end{array}$ & $\begin{array}{l}27 \\
30\end{array}$ & $\begin{array}{l}\text { No } \\
\text { Yes }\end{array}$ & $\begin{array}{r}0 \\
40\end{array}$ & $\begin{array}{l}160 \\
160\end{array}$ & $\begin{array}{l}110 \\
110\end{array}$ \\
\hline
\end{tabular}

TABLE IV-Estimated event rates for levels of risk factors detailed in table III

Estimated event rates/1000 patient years ${ }^{\star}$

\begin{tabular}{|c|c|c|c|c|c|c|c|c|c|}
\hline & \multicolumn{3}{|c|}{ Myocardial infarction } & \multicolumn{3}{|c|}{ Stroke } & \multicolumn{3}{|c|}{ All cardiovascular events } \\
\hline & Placebo & Propranolol & Bendrofluazide & Placebo & Propranolol & Bendrofluazide & Placebo & Propranolol & Bendrofluazide \\
\hline $\begin{array}{l}\text { Low risk } \\
\text { High risk }\end{array}$ & $\begin{array}{l}2 \cdot 4 \\
88\end{array}$ & $\begin{array}{c}1.8 \\
119\end{array}$ & 85 & 61 & $\begin{array}{l}0 \cdot 8 \\
67\end{array}$ & $\begin{array}{l}0 \cdot 5 \\
12\end{array}$ & $\begin{array}{c}3 \cdot 7 \\
149\end{array}$ & $\begin{array}{c}2 \cdot 6 \\
186\end{array}$ & $\begin{array}{l}2 \cdot 9 \\
97\end{array}$ \\
\hline
\end{tabular}

^Rates for myocardial infarction and stroke calculated from logistic regression analysis on variables at entry. "All cardiovascular events" calculated as sum of rates for myocardial infarction and stroke.

TABLE V-Estimated benefits of treatment in relation to risk factors (table III) and event rates (table IV)

\begin{tabular}{|c|c|c|c|c|c|c|c|c|c|c|c|c|}
\hline & \multicolumn{6}{|c|}{ Relative benefit (\%) } & \multicolumn{6}{|c|}{ No of patients to be treated for five years to avoid one event } \\
\hline & \multicolumn{2}{|c|}{ Myocardial infarction } & \multicolumn{2}{|c|}{ Stroke } & \multicolumn{2}{|c|}{ All cardiovascular events } & \multicolumn{2}{|c|}{ Myocardial infarction } & \multicolumn{2}{|c|}{ Stroke } & \multicolumn{2}{|c|}{ All cardiovascular events } \\
\hline & Propranolol & Bendrofluazide & Propranolol & Bendrofluazide & Propranolol & Bendrofluazide & Propranolol & Bendrofluazide & Propranolol & Bendrofluazide & Propranolol & Bendrofluazide \\
\hline Low risk & 27 & 0 & 38 & 64 & 30 & 22 & 308 & - & 405 & 242 & 182 & 262 \\
\hline High risk & - & 4 & - & 80 & - & 35 & - & 58 & - & - & - & 4 \\
\hline
\end{tabular}

the low risk patient, even though the low risk patient has the same raised pressure and might be expected to benefit substantially from treatment. About four high risk patients would need to be treated for five years in order to avoid one stroke, whereas 242 low risk patients would have to be treated for five years in order to avoid one stroke. Propranolol provides no benefit because the high risk patient in the example is also a heavy smoker. The implications of treatment for preventing myocardial infarction, particularly in non-smoking men, are considered in detail elsewhere. ${ }^{7}$

Our results do not support a $\mathrm{J}$ shaped relation between blood pressure and the incidence of myocardial infarction in either the placebo or actively treated group, though they do not conclusively rule out the possibility either. This issue can probably be resolved only by a further trial.

All recommendations about treatment must be based on a consideration of adverse drug effects as well as of benefits. Overall, reactions serious enough to lead to withdrawal of a drug were more frequent, in men, with bendrofluazide than with propranolol, ${ }^{8}$ the excess being mainly attributable to impaired glucose tolerance, gout, and impotence. Where less serious or less easily definable reactions were concerned bendrofluazide was apparently better tolerated than propranolol. Some reactions to bendrofluazide, such as dizziness, were dose related, ${ }^{9}$ so their incidence would be less with doses given currently than in this trial; and inclusion in a trial where precise adherence to a protocol is necessary tends to increase the apparent burden of adverse reactions. None the less, data from this trial for the incidence of serious adverse reactions-with rates for impaired glucose tolerance, gout, and impotence of roughly $33 / 1000$ person years of treatment with bendrofluazide compared with 11 with propranolol-add to the evidence that propranolol would be preferable for non-smokers. The incidence of serious reactions associated with bendrofluazide was about three per 20 patients treated for five years compared with one per 20 patients treated for five years with propranolol, a considerable excess attributable to bendrofluazide. (Smoking did not apparently affect the incidence of adverse reactions.) We also emphasise that all results, including the beneficial effects, can be related only to the dose of $10 \mathrm{mg}$ bendrofluazide used in the trial. Though $5 \mathrm{mg}$ bendrofluazide has equal hypotensive effects and fewer adverse reactions, ${ }^{7}$ this does not necessarily apply to the beneficial effects on event rates.

A rational treatment policy should be based on four main considerations: $(a)$ the significant reduction in stroke rate with active treatment; $(b)$ the absence of a significant difference in coronary event rates between active and placebo treatments; $(c)$ the knowledge that if 100 men in the highest risk group-that is, men aged 55-64 with high entry systolic pressure who smoke-were to be observed for five years without drug treatment five would be expected to suffer a stroke and 10 a myocardial infarction; and (d) the cost of prolonged treatment, both in terms of adverse drug reactions as well as financial.

Of a high risk group of 100 men given bendrofluazide, one or two might suffer a stroke and 10 a myocardial infarction during the next five years. For a group of 100 non-smoking men in the highest risk categories of age and blood pressure propranolol for five years would probably result in a reduction of the number having strokes from three to one or two and might possibly reduce the number having a myocardial infarction from seven to four. Smokers treated with propranolol would not be expected to benefit. The implications in women are less certain, partly because of the smaller number of events, but not smoking is particularly important. The considerations for preventing stroke are similar to those in men, but no clear guideline is possible on the effect of lowering blood pressure for preventing myocardial infarction in women.

We thank the general practitioners and nurses belonging to the research framework; Professor H D Tunstall Pedoe for assessing all terminating events; Professor T P Whitehead and the staff of the Wolfson Research Laboratories, Queen Elizabeth Medical Centre, Birmingham, for carrying out the biochemical analyses; Duncan, Flockhart and Co Ltd for tablets of bendrofluazide and placebo; Imperial Chemical Industries Ltd for financial support and for tablets of propranolol and placebo; CIBA Laboratories for 
supplies of guanethidine; and Merck Sharp and Dohme Ltd for a mobile screening unit, funds for its staffing, and supplies of methyldopa.

\section{References}

1 Medical Research Council Working Party. MRC trial of treatment of mild hypertension: principal results. Br Med f 1985;291:97-104.

2 Kannel WB, Sorlie P, Gordon T. Labile hypertension: a faulty concept? The Framingham study. Circulation 1980;61:1183-7.

3 Cruickshank JM, Thorp JM, Zacharias FJ. Benefits and potential harm of lowering high blood pressure. Lancet 1987;i:581-4.

4 Berglund G, Samuelsson O. Lowered blood pressure and the J-shaped curve. Lancet 1987;i:1154-5.
5 IPPPSH Collaborative Group. Cardiovascular risk and risk factors in a randomised trial of treatment based on the beta-blocker oxprenolol: the international prospective primary prevention study in on the beta-blocker oxprenolol: the international prospective

6 Cruickshank JM. MRC tria

7 Medical Research Council Working Party. Coronary heart disease in the MRC trial of treatment of mild hypertension. Br Heart $\mathcal{F}$ 1988;59:364-78.

8 Medical Research Council Working Party on Mild to Moderate Hypertension. Adverse reactions to bendrofluazide and propranolol for the treatment of mild hypertension. Lancet 1981;ii:539-43.

9 Medical Research Council Working Party. Comparison of the antihypertensive efficacy and adverse reactions to two doses of (i) bendrofluazide and (ii) hydrochlorothiazide, and the effect of potassium supplementation on the hypotensive action of bendrofluazide. 7 Clin Pharmacol $1987 ; 27: 271-7$.

(Accepted 12 February 1988)

\title{
Protective efficacy of a whole cell pertussis vaccine
}

\author{
MARGARETA BLENNOW, PATRICK OLIN, MARTA GRANSTRÖM, ROGER H BERNIER
}

\begin{abstract}
A trial of the efficacy of a plain whole cell pertussis vaccine was conducted in Sweden. In this non-blinded trial 525 infants aged 2 months who were born on days with an even number received three doses of vaccine one month apart and 615 infants of the same age who were born on days with an odd number were enrolled as controls. During the $\mathbf{1 8}$ months of follow up there were 55 cases of pertussis. The attack rate was $1.5 \%(8 / 525)$ among the vaccinated children and $7 \cdot 6 \%(47 / 615)$ among the unvaccinated children $(p<0.001)$. The estimated efficacy of the vaccine was $80 \%$ ( $95 \%$ confidence interval 58 to 90 ).

The estimated efficacy of pertussis vaccine was similar to that observed in British trials over $\mathbf{3 0}$ years ago.
\end{abstract}

\section{Introduction}

A national immunisation programme against pertussis was introduced in Sweden, as in many other countries, in the mid-1950s. After years of the incidence of the disease decreasing epidemics of pertussis started to occur in the 1970s. This resurgence was associated with a decreased efficacy of the vaccine and together with a growing concern about the safety of the vaccine led to the decision in 1979 to stop the routine use and production of pertussis vaccine. A plain whole cell vaccine (Pertussis Vaccine Wellcome; Wellcome) was imported from the United Kingdom in 1981 for limited use in children with cystic fibrosis and other conditions of high risk. ${ }^{12}$

The possibility that a further increase in the incidence of the disease would necessitate reintroducing general vaccination prompted further studies of Wellcome's product. Our study was started in 1982 to collect information on the antibody response and adverse

Karolinska Institute, Department of Paediatrics, Sachs's Children's Hospital, and Department of Vaccine Production, National Bacteriological Laboratory, Stockholm, Sweden

MARGARETA BLENNOW, MD, paediatrician

PATRICK OLIN, MD, associate professor

MARTA GRANSTRÖM, MD, associate professor

Division of Immunization, Centers for Disease Control, Atlanta, Georgia 30333, United States

ROGER H BERNIER, MPH, PHD, chief, epidemiology research section

Correspondence to: $\operatorname{Dr} M$ Blennow, Department of Vaccine Production, National Bacteriological Laboratory, S-105 21 Stockholm, Sweden. reactions to the vaccine and the protective efficacy of the vaccine. The data on side effects and serological efficacy by the neutralisation test have been presented elsewhere. ${ }^{34}$ This report investigates the efficacy of the vaccine in the clinical trial.

\section{Subjects and methods}

From mid-1982 to mid-1983 2 month old infants enrolled at 51 preventive care child health centres in Stockholm who had no known contraindications to pertussis vaccination ${ }^{5}$ were identified to participate in a non-blinded trial. Consent to participate was obtained from all the parents. Infants born on days with an even number were inoculated subcutaneously with three $0.5 \mathrm{ml}$ doses of vaccine given one month apart, starting from the age of 2 months (mean $2 \cdot 3$ (SD 0.5) months, range $1 \cdot 2-7 \cdot 3$ months). Children of the same age born on days with an odd number received no pertussis vaccine. Nurses at the child health centres were instructed to ask parents during the normal regular visits (every 2-4 months) whether the infants in the study had had pertussis and to note any symptoms on a special form kept in the medical records at the centres. Paediatricians at the primary care facilities affiliated with these centres were asked to examine all participants with suspected pertussis and report their findings on a special form.

In February 1985 the report forms of partcipating infants were collected to ascertain the number of cases of pertussis that had occurred in the study population between the ages of 6 and 23 months. In addition, the regular medical records kept at the child health centres were reviewed and the files of laboratory reports to the National Bacteriological Laboratory in Stockholm searched for positive results on culture for children in the study. This laboratory is a governmental agency that receives reports on all positive cultures for pertussis from laboratories throughout Sweden. All samples taken for serological tests from children in the study were identified by a systematic search in the files of the only two laboratories that perform routine serological tests for pertussis. The samples were retested by methods indicated below.

Cases of pertussis were considered to be confirmed by the laboratory if they yielded positive results on culture for Bordetella pertussis or positive serological findings, which were defined as a significant rise in titres in an enzyme linked immunosorbent assay (ELISA) to detect antibodies against filamentous haemagglutinin and pertussis $\operatorname{toxin}^{67}$ or in a neutralisation test in Chinese hamster ovary cells to detect antibodies against pertussis toxin, ${ }^{89}$ or both. $B$ pertussis was cultured in routine laboratories and therefore the serotypes were unknown. The serological assays used were found to have a diagnostic sensitivity in terms of raised titres of $100 \%$ in 90 cases of pertussis that were confirmed by the results of culture (unpublished data).

Cases of pertussis that were not confirmed by laboratory results were included if infants had had typical symptoms such as coughing for more than four weeks, whoops, or coughing with vomiting. In addition, whooping cough had to have been diagnosed by a doctor or have been linked epidemiologically - that is, the infant had been in contact with another patient with whooping cough-or both. These data were supplemented by contacting the parents and the doctors who had diagnosed the disease. 